\title{
Uso de medicamentos fitoterápicos em pediatria
}

\author{
Use of herbal drugs in pediatrics \\ Uso de drogas herbales en pediatría
}

\author{
Thaise de Abreu Brasileiro Sarmento \\ ORCID: https://orcid.org/0000-0003-0390-805X \\ Universidade Federal de Campina Grande, Brasil \\ E-mail: thaiseabreu@hotmail.com \\ Antônio Fernandes Filho \\ ORCID: https://orcid.org/0000-0002-3111-7610 \\ Universidade Federal de Campina Grande, Brasil \\ E-mail: antonio.fernandes@professor.ufcg.edu.br \\ Ankilma do Nascimento Andrade Feitosa \\ ORCID: https://orcid.org/0000-0002-4751-2404 \\ Faculdade Santa Maria, Brasil \\ E-mail: ankilmar@hotmail.com \\ Patrício Borges Maracajá \\ ORCID: https://orcid.org/0000-0003-4812-0389 \\ Universidade Federal de Campina Grande, Brasil \\ E-mail: patriciomaracaja@gmail.com \\ Anubes Pereira de Castro \\ ORCID: https://orcid.org/0000-0002-3795-5666 \\ Universidade Federal de Campina Grande, Brasil \\ E-mail: anubescastro@gmail.com
}

\begin{abstract}
Resumo
Objetivo: Discutir o uso da fitoterapia adotada como terapêutica em crianças atendidas em ambulatórios de pediatria. Metodologia: Estudo exploratório, descritivo e transversal com abordagem quali-quantitativa. A pesquisa ocorreu na Policlínica Santa Maria, Policlínica Orcino Guedes e Polisaúde, ambos com atendimento em pediatria e localizadas no município de Cajazeira-PB. A amostra do estudo foi composta por 324 pais/responsáveis das crianças atendidas nos ambulatórios mencionados, sendo a coleta dos dados realizada nos meses de agosto, setembro e outubro de 2021, através de um instrumento validado sobre a saúde e utilização de plantas medicinais em crianças pelas famílias. Para análise dos dados utilizou-se o programa SPSS v.25, além dos testes inferenciais de qui-quadrado de Pearson, além da técnica proposta por Bardin. Os critérios de inclusão foram: pais/responsáveis por crianças de 0-10 anos atendidas nos ambulatórios, no período correspondente à realização da pesquisa e que preencheram o formulário, sendo excluídos aqueles que não preencheram o questionário corretamente e aqueles que não sabiam informar sobre o uso de fitoterápicos. Resultados: Foi analisado que as plantas medicinais mais utilizadas no município de Cajazeiras foi: camomila (17,5\%) seguida de cidreira $(8,8 \%)$ e Boldo (8\%). Além disso, foi identificado que $73,1 \%$ dos entrevistados utilizam ou já utilizaram as plantas medicinais para prevenção, cura ou tratamento de doenças em seus filhos, dos quais $90,29 \%$ receberam orientações dos próprios familiares. 219 entrevistados informaram que usam as plantas como chás. Conclusão: Visto isso, observou-se que a utilização de plantas medicinais é fortemente presente entre os pais do município de Cajazeiras-PB.
\end{abstract}

Palavras-chave: Fitoterapia; Saúde da criança; Assistência ambulatorial.

\begin{abstract}
Objective: To discuss the use of herbal medicine adopted as therapy in children seen in pediatric outpatient clinics. Methodology: Exploratory, descriptive and cross-sectional study with a quali-quantitative approach. The research took place at Policlínica Santa Maria, Policlínica Orcino Guedes and Polisaúde, both with pediatric care and located in the city of Cajazeira-PB. The study sample consisted of 324 parents/guardians of children assisted in the aforementioned clinics, with data collection carried out in August, September and October 2021, through a validated instrument on the health and use of medicinal plants in children by the families. For data analysis, the SPSS v.25 program was used, in addition to Pearson's inferential chi-square tests, in addition to the technique proposed by Bardin. Inclusion criteria were: parents/guardians of children aged 0-10 years seen at the clinics, in the period corresponding to the research and who completed the form, excluding those who did not fill out the questionnaire correctly and those who were unable to inform about the use of herbal medicines. Results: It was analyzed that the most used medicinal plants in the city of Cajazeiras were: chamomile (17.5\%) followed by lemongrass $(8.8 \%)$ and Boldo (8\%). In addition, it was identified that $73.1 \%$ of respondents use or have used medicinal plants for the prevention, cure or treatment of diseases in their children, of which $90.29 \%$ received guidance from their own family
\end{abstract}


members. 219 respondents reported using the plants as teas. Conclusion: Having said that, it was observed that the use of medicinal plants is strongly present among parents in the city of Cajazeiras-PB.

Keywords: Phytotherapy; Child health; Ambulatory care.

\begin{abstract}
Resumen
Objetivo: discutir el uso de la medicina herbal adoptada como terapia en niños atendidos en clínicas ambulatorias pediátricas. Metodología: Estudio exploratorio, descriptivo y transversal con enfoque cuali-cuantitativo. La investigación se llevó a cabo en Policlínica Santa Maria, Policlínica Orcino Guedes y Polisaúde, ambas con atención pediátrica y ubicadas en la ciudad de Cajazeira-PB. La muestra del estudio estuvo conformada por 324 padres / tutores de niños atendidos en las clínicas mencionadas, con recolección de datos realizada en agosto, septiembre y octubre de 2021, a través de un instrumento validado sobre la salud y uso de plantas medicinales en niños por parte de las familias. Para el análisis de los datos se utilizó el programa SPSS v.25, además de las pruebas de chi-cuadrado inferencial de Pearson, además de la técnica propuesta por Bardin. Los criterios de inclusión fueron: padres / tutores de niños de 0-10 años atendidos en las clínicas, en el período correspondiente a la investigación y que cumplimentaron el formulario, excluyendo a los que no cumplimentaron correctamente el cuestionario y a los que no pudieron informar sobre el uso de medicamentos a base de hierbas. Resultados: Se analizó que las plantas medicinales más utilizadas en la ciudad de Cajazeiras fueron: manzanilla (17,5\%) seguida de limoncillo $(8,8 \%)$ y boldo (8\%). Además, se identificó que el $73,1 \%$ de los encuestados utiliza o ha utilizado plantas medicinales para la prevención, cura o tratamiento de enfermedades en sus hijos, de los cuales el 90,29\% recibió orientación de sus propios familiares. 219 encuestados informaron que usaban las plantas como tés. Conclusión: Dicho esto, se observó que el uso de plantas medicinales está fuertemente presente entre los padres en la ciudad de Cajazeiras-PB.
\end{abstract}

Palabras clave: Fitoterapia; Salud del niño; Atención ambulatoria.

\title{
1. Introdução
}

Ao passar dos anos os seres humanos coevoluiram juntamente ao meio botânico, o qual lhe auxiliou como uma fonte de abrigo, alimento e recursos terapêuticos, o que constituiu um meio simbólico de costumes e rituais tradicionais mantidos consecutivamente pelas civilizações (Duarte et al., 2020). Ações consuetodinárias no cuidado à saúde através da utilização de ervas e plantas vem sendo empregadas desde que os humanos iniciaram os seus registros informais na cura de grupos tribais e, posteriormente, no cuidado comunitário e familiar (Brito et al., 2017).

O alimento, que anteriormente era embutido a fonte de saúde e valor nutricional, passou a atender, o mercado que lhes atribui o único papel de ser mercadoria, mesmo fora do cômpito de "commodities" (Silva, 2017). Dessa forma, o alimento perde a sua natureza integrativa de nutrir saudavelmente. Visto isso, a disponibilização dos recursos cresce com o intuito de compensar a insuficiência, principalmente, através das indústrias farmacêuticas, a qual reclamam de serem o único caminho para a cura das doenças (Rückert et al., 2018).

O conhecimento adquirido pela população sobre a utilização de plantas como recursos terapêuticos proporciona a população um empoderamento, já que muitas plantas utilizadas por estes já tem uma eficácia comprovada cientificamente, sendo muito efetiva no controle de diversas enfermidades (Leite, 2019). O Brasil, por possuir uma das maiores biodiversidades mundial, possui um grande grupo de população que detem do conhecimento sobre a cura advinda de extratos, sucos e chás de plantas que funcionam como agentes medicamentosos (Fernandes et al., 2017).

Com o passar dos anos muitas doenças infecto-contagiosas por não serem mais controladas por meio da utilização de vacina ou antibiótico, levantou em questão a necessidade de investigações científicas, que deram origem as práticas de terapias milenares (Duarte et al., 2020).

No Brasil a prática de utilização de plantas para fins medicinais é regulada pela Política Nacional de Plantas Medicinais e Fitoterápicos (PNPMF), que foi aprovada através do decreto $\mathrm{n}^{\circ} 5.813$ de 22 de junho de 2006 por meio da portaria 971 do Ministério da Saúde (MS), com objetivos voltados para a garantia do acesso racional e seguro das plantas de forma consciente e racional através da utilização de tecnologias e inovações promovendo um desenvolvimento complexo e produtivo para a saúde. Além de conservar a flora, a política também incentiva o conhecimento e a utilização das plantas medicinais (Brasil, 2016). 
A criação da política, de âmbito nacional, foi o resultado de lutas que remonta a época da criação do Sistema Único de Saúde (SUS), onde pesquisadores, profissionais, gestores e usuários tiveram papeis fundamentais. Uma vez que a utilização dos fitoterápicos no SUS representa o resgate de práticas culturais antigas, envolvendo o conhecimento popular e científico para o tratamento de inúmeras doenças. No entanto, a utilização desses dois tipos de conhecimentos, muitas vezes gera divergências sobre a utilização do mesmo (Brasil, 2006).

A utilização de plantas pela comunidade rural é uma prática relacionada a etnobotânica, onde o número expressivo dessas plantas utilizadas cotidianamente pela população é vasta, demonstrando sérios risco a saúde devido a utilização equivocada das plantas (Cavalcante et al., 2014). No entanto, a saída dessa população para a área urbana ocasionou uma grande perca sobre os conhecimentos e a utilização de plantas (Moraes et al., 2019). Em um realizado por Oliveira et al. (2010), com indivíduos que residiam em algumas comunidades rurais do semiárido piauiense, foi apontado que há uma diversidade de 167 espécies medicinais nestas comunidades. Duarte (2020) também relata que 149 espécies de plantas são utilizadas para fins terapêuticos, em comunidades rurais da região do Planalto Sul Catarinense, já no estudo de Baracuhy et al. (2016) foram utilizadas 50 espécies de plantas medicinais na região Nordeste do país.

No Estado da Paraíba a utilização das plantas medicinais utilizadas por moradores da zona rural de Bananeiras, foi na forma de folhas para a preparação de chás, seguida de frutos e raízes. Onde a maioria dessa população utiliza as plantas com frequência devido a sua acessibilidade econômica, sendo a prática repassada de pai para filho. Na região foram citadas 45 espécies de plantas pertencentes a 31 famílias, evidenciando o rico conhecimento etnobotânico da população local (Cavalcante et al., 2014).

O reassentamento e a movimentação urbana das famílias oriundas do meio rural influem, marcadamente, no reconhecimento popular, tradicionalmente, praticado pela comunidade urbana (Sá et al., 2019). Visto isso, a incidência no conhecimento popular se apresenta mais vulnerável nas comunidades onde o acesso aos serviços de saúde pública é facilitado. Segundo Pinto et al. (2006), a frequência com que os moradores realizam consultas médicas e usam farmácias acabam por reduzir as práticas medicinais populares. Além disso, no estudo de Rodrigues et al. (2013) foi relatada a utilização de plantas medicinais em crianças, sobretudo na forma de chás e lambedor, no entanto, grande parcela dos pais ou cuidadores $(25,8 \%)$ não informou ao médico essa prática. Esses autores apontam a necessidade do incentivo e fortalecimento das práticas da população acerca do uso de plantas para fins medicinais, sobretudo ofertadas para crianças.

Dessa forma, o estudo tem como objetivo discutir o uso da fitoterapia adotada como terapêutica em crianças atendidas em ambulatórios de pediatria.

\section{Metodologia}

Foi realizado uma pesquisa do tipo exploratória, descritiva e transversal com uma abordagem quali-quantitativa.

A pesquisa exploratória e descritiva tem como objetivo definir melhor um problema, descrevendo comportamentos de fenômenos, definindo e classificando variáveis e fatos, proporcionando a solução dos mesmos (Salomon, 2004).

Já para Andrade (2009) na pesquisa descritiva os fatos são observados, registrados, analisados, classificados e interpretados sem que haja interferências de pesquisadores, deste modo os eventos são estudados sem a manipulação do mesmo. Uma das características desse tipo de pesquisa é que a técnica da coleta de dados é padronizada, e realizada, principalmente pela elaboração de questionários e da observação sistemática.

Segundo Prodanov e Freitas (2013) a pesquisa quantitativa utiliza a coleta dos dados para testar as hipóteses, baseando-se na medição numérica e análise estatística, no qual permite generalizar os dados obtidos e pode ser replicado. Já a pesquisa qualitativa se caracteriza como uma busca pela compreensão mais detalhada das características e significados situacionais apresentados pelos entrevistados, em lugar da produção de medidas quantitativas de comportamentos 
características.

O estudo ocorreu em três instituições que prestam atendimentos a crianças: a Policlínica Santa Maria, Policlínica Orcino Guedes e Consultório da Polisaúde, para que possam ser identificadas as plantas medicinais avaliando os conhecimentos familiar acerca da utilização dessas plantas. As instituições estão localizadas no Município de Cajazeiras, que está situada na região oeste do estado da Paraíba, nas coordenadas geográficas $38^{\circ} 23$ ' $42^{\prime}$ ' de longitude oeste e $6^{\circ} 53$ ' 13 ” de latitude sul, distante cerca de 468 quilômetros da capital, João Pessoa, ocupando uma extensão territorial de 565,899 km², 298 $\mathrm{m}$ de altitude quando comparada ao nível do mar com clima seco e quente (temperatura varia de $23^{\circ} \mathrm{C}$ a $30^{\circ} \mathrm{C}$ ), sendo sua população constituída por 58.446 (cinquenta e oito mil, quatrocentos e quarenta e seis) habitantes, com uma densidade demográfica de 97,7/km2 (IBGE, 2017). Além disso, o município está situado nos domínios da sub-bacia do Rio do Peixe e na bacia hidrográfica do Rio Piranhas, sendo a vegetação dominante a caatinga.

Dessa forma a população consiste em um conjunto de todos os elementos que apresentam certas características em comum. A amostra constitui um subconjunto da população, sendo através dela que se permite estabelecer ou estimar as características da população (Gil, 2002).

A população do estudo foi composta por pacientes que serão atendidos em três ambulatórios da cidade de Cajazeiras, a coleta dos dados ocorreu durante os meses de Agosto, Setembro e Outubro de 2021, conforme média mensal de atendimento: Policlínica da Faculdade Santa Maria (FSM) e a Policlínica Orcino Guedes, ambas com a realização média de 40 atendimentos mensais e 120 trimestrais; no Consultório da Polisaúde são realizados 60 atendimentos mensais e 180 atendimentos trimestrais. Em três meses foram atendidos uma média de 420 pacientes, para isso foi calculado a perspectiva da amostra que participou da pesquisa.

Considerando uma população finita de 420 pessoas atendidas nas policlínicas da FSM (03 meses = 120 pessoas); da Policlínica Orcino Guedes $(03$ meses $=120)$ e da Polisaúde $(03$ meses $=180$ pessoas $)$, uma prevalência de 0.5 , erro absoluto tolerável (d) de 0.05 e um coeficiente de confiança de 95\%, estimou-se uma amostra de 188 pessoas que foram estratificadas proporcionalmente entre as três unidades (policlínica da FSM 54 pessoas; Policlínica Orcino Guedes 53 pessoas e Polisaúde 81). Além disso, na abordagem qualitativa foram entrevistados os responsáveis quanto a utilização de fitoterápicos.

Dessa forma, a fórmula de populações finitas (figura 1) é usada quando a população possui menos de 100 mil sujeitos ou quando a amostra será menor do que $5 \%$ da população.

Figura 1. Fórmula amostral para amostras finitas.

$$
n=\frac{z_{(1-\gamma) / 2}^{2} N p(1-p)}{d^{2}(N-1)+z_{(1-\gamma) / 2}^{2} p(1-p)}
$$

Fonte: Levine et al. (2000)

Foi utilizado um instrumento validado por Alves et al. (2003). O questionário semiestruturado, composto por 6 questões objetivas e subjetivas com questões relacionadas à saúde e a utilização de plantas medicinais em crianças pela família.

Vale ressaltar, que a coleta só ocorreu após aprovação do Comitê de Ética em Pesquisa da Universidade Federal de Campina Grande. Os dados quantitativos coletados foram apresentados em tabelas, enquanto os qualitativos foram dispostos através da análise dos conteúdos.

Os dados foram analisados através do programa SPSS (Versão 25). Além de estatística descritiva de frequência relativa e absoluta, também foram usados testes inferenciais de qui-quadrado de Pearson adotando uma significância estatística 0,20 para entrada em um modelo multivariado de regressão de Poisson.

Para a análise qualitativa dos dados, as informações obtidas foram submetidas à técnica da análise de conteúdo que 
proporciona elucidar o tema que, é a unidade de significação que se liberta de um texto analisado segundo critérios relativos à teoria que serve de guia à leitura (Bardin, 2011).

Visto isso, a análise dos dados proposta por Bardin (2011) segue através de três etapas, uma pré-análise, descrição analítica e interpretação referencial. A pré-análise consiste na organização do material através da seleção dos documentos; na descrição analítica, os documentos passam por uma análise profunda, o que toma como base as referências e as hipóteses. Neste momento, são criados temas de estudo e se pode fazer uma codificação, classificação e/ou categorização, além da interpretação referencial ser a fase na qual através dos dados empíricos e informações coletadas, se estabelecem as relações entre o objeto de análise e o seu contexto mais amplo, chegando, até mesmo, a reflexões que estabeleçam novos paradigmas nas estruturas e relações estudadas.

Deste modo, o projeto foi encaminhado para aprovação do Comitê de Ética e Pesquisa da Universidade Federal de Campina Grande, campus Cajazeiras-PB para análise, recebendo o parecer $n^{\circ}$ 4.872.254 e CAAE $n^{\circ}$ 47911821.0.0000.5575, para assim dar início a coleta dos dados.

Visto isso, foi garantido aos participantes do estudo todo o esclarecimento necessário, bem como, absoluto sigilo das informações obtidas durante todas as etapas. Antes do início das entrevista, o Termo de Consentimento Livre e Esclarecido (TCLE) foi apresentado, assinado e a partir da concordância do entrevistado, prosseguiu com a entrevista e a mesma pode ser interrompida assim que o entrevistado desejasse.

Foram incluídos pais ou responsáveis de crianças com de até 10 anos atendidas nos ambulatórios ora mencionados, no período de 3 (três) meses e que preencham todo o formulário. Sendo excluídos os que não preencheram o questionário corretamente e aqueles que não informaram sobre o uso de fitoterápicos.

\section{Resultados}

A tabela 1 mostra que 73,1\% das pessoas utilizaram plantas medicinais para o seus filhos e que a forma mais comum de aceso ao conhecimento foi em casa, com os pais ou avós.

Tabela 1. Uso e acesso às plantas medicinas.

\begin{tabular}{lccc}
\hline & F & \% \\
\hline Utilizou plantas medicinais para o tratamento de doenças em seus filhos & & 26,9 \\
& Não & 87 & 73,1 \\
Sim & 237 & \\
Como teve acesso ao conhecimento das plantas medicinais* & & 90,29 \\
& Em casa, com os pais ou avós & 214 & 1,69 \\
& Livros ou revistas & 4 & 0,0 \\
& Acordo com crenças ou tradições & 0 & 2,53 \\
& vizinhos, conhecidos, amigos & 6 & 2,11 \\
& Profissional da saúde & 5 & $* *$ \\
Qual & Médico & 1 & $* *$ \\
& Pédicos & 1 & $* *$ \\
& Cultra & 2 & 3,38 \\
Outros $\quad$ Internet & 8 & $* *$ \\
& Medicamento fitoterapêutico. & 4 & $* *$ \\
& Na igreja & 2 & $* *$ \\
& & 1 & $* *$ \\
\hline
\end{tabular}

Nota: * porcentagem baseada nos 237 participantes que usam plantas. ** porcentagem relativa a última categoria de resposta. Fonte: Dados da pesquisa (2021). 
A Tabela 2 mostra, em ordem decrescente, as plantas que foram utilizadas pela amostra. A Camomila, seguida de Cidreira e Boldo foram as mais relatadas.

Tabela 2. Descrição das plantas utilizadas.

\begin{tabular}{lc|ll}
\hline Nome & F $(\boldsymbol{\%})$ & Nome & F (\%) \\
\hline Camomila & $92(17,5)$ & Semente de girassol & $2(0,4)$ \\
Cidreira & $46(8,8)$ & Beterraba & $2(0,4)$ \\
Boldo & $42(8)$ & Flor de sabugo & $2(0,4)$ \\
Erva doce & $39(7,4)$ & Chá de vassourinha & $2(0,4)$ \\
Malva & $37(7)$ & Umburana & $2(0,4)$ \\
Hortelã & $37(7)$ & Noz-moscada & $2(0,4)$ \\
Capim santo & $27(5,1)$ & Flor de goiabeira & $1(0,2)$ \\
Endro & $26(5)$ & Casca de jurema & $1(0,2)$ \\
Macela & $21(4)$ & Raiz de vassourinha & $1(0,2)$ \\
Eucalipto & $19(3,6)$ & Chá de menta & $1(0,2)$ \\
Alho & $13(2,5)$ & Chá de quebra pedra & $1(0,2)$ \\
Alfazema & $11(2,1)$ & Cabelo de milho & $1(0,2)$ \\
Cebola & $11(2,1)$ & Hibisco & $1(0,2)$ \\
Romã & $10(1,9)$ & Chá verde & $1(0,2)$ \\
Chá preto & $8(1,5)$ & Chamalis & $1(0,2)$ \\
Canela & $6(1,1)$ & Flor de mamão & $1(0,2)$ \\
Folha de laranja & $6(1,1)$ & Folha de manga & $1(0,2)$ \\
Chanona & $4(0,8)$ & Diurese de gato & $1(0,2)$ \\
Alecrim & $4(0,8)$ & Açafrão & $1(0,2)$ \\
Arruda & $4(0,8)$ & Espinho de cigano & $1(0,2)$ \\
Chá de sabugueiro & $4(0,8)$ & Manteiga da terra & $1(0,2)$ \\
Xarope caseiro & $4(0,8)$ & Melaço & $1(0,2)$ \\
Chá de entrecoxas & $4(0,8)$ & Genipapo & $1(0,2)$ \\
Lambedor de mel com limão & $4(0,8)$ & Folha de graviola & $1(0,2)$ \\
Coentro & $3(0,6)$ & Folha de lavro & $1(0,2)$ \\
Mentruz & $3(0,6)$ & Chá de abacaxi & $1(0,2)$ \\
Juá & $3(0,6)$ & Raspa de coco & $1(0,2)$ \\
Chá de picão & $3(0,6)$ & Melaço & $1(0,2)$ \\
\hline
\end{tabular}

Fonte: Dados da pesquisa (2021).

A Tabela 3 mostra que as plantas eram usadas na maioria das vezes com Chás ou xaropes e foram obtidas, para a maioria das pessoas, na própria residência, no mercado e em vendedores de rua.

Tabela 3. Descrição de como as plantas eram usadas e obtidas.

\begin{tabular}{lcc}
\hline & F & \% \\
\hline Como as plantas eram usadas* & 219 & 92,40 \\
Chás & 2 & 0,84 \\
Tinturas & 56 & 23,63 \\
Xaropes & 3 & 1,27 \\
Óleos & 0 & 0,0 \\
Pomadas & 1 & 0,42 \\
Cataplasmas & 0 & 0,0 \\
Cápsulas & & \\
Em plantações da própria casa & 123 & 51,89 \\
Com vizinhos & 13 & 5,49 \\
Comprados em algum tipo de mercado & 89 & 37,55 \\
Vendedor de rua & 30 & 12,66 \\
Outros & 6 & 2,53 \\
\hline
\end{tabular}

Nota: * Algumas pessoas usaram mais de uma planta e conseguiram em mais de um lugar, por isso a porcentagem dará um valor maior do que 100. Fonte: Dados da pesquisa (2021). 
A maioria das pessoas relataram que as plantas tiveram efeito no problema de saúde.

Tabela 4. Descrição dos efeitos das plantas.

\begin{tabular}{ccc}
\hline & F & $\%$ \\
\hline Plantas surtiram o efeito desejado & 13 & 5,5 \\
Não & 224 & 94,5 \\
Sim & & \\
Motivo de não terem surtido efeito desejado* & 1 & 7,69 \\
Era para fazer a vontade dos avós & 1 & 7,69 \\
Ficava do mesmo jeito. & 1 & 7,69 \\
Não acalmou. & 2 & 15,38 \\
Não aliviava & 1 & 7,69 \\
Não amenizou a asma & 1 & 7,69 \\
Não dormiu e não melhorou a cólica. & 1 & 7,69 \\
Não evacuou & 1 & 7,69 \\
Não foi resolvido a icterícia. & 1 & 7,69 \\
Não passaram as cólicas. & 1 & 7,69 \\
Não serviu. & 1 & 7,69 \\
Não surtiu efeito. & 1 & 7,69 \\
Uso incorreto ou pouca frequência. & & \\
\hline
\end{tabular}

Nota: * porcentagem calculada com base nos 13 que relataram não ter tido efeito desejado. Fonte: Dados da pesquisa (2021).

\section{Discussão}

As plantas medicinais representam um riquíssimo arsenal de produtos químicos, inorgânicos e orgânicos com diferentes características para a exploração humana. Na maioria das vezes estas são utilizadas como forma de terapia complementar a tratamentos prescritos por médicos, sendo este influenciado por práticas culturais ou indicação de amigos e familiares. Dessa forma, a orientação realizada por profissionais de saúde, ao consumo das plantas medicinais vem aumentando, sendo estes incentivos por políticas, mídias sociais ou para fins estéticos, como por exemplo o emagrecimento (Pedroso et al., 2020).

Silva et al. (2021) ainda mostram em seu estudo que cerca de $80 \%$ de toda a população mundial ainda dependem dos princípios ativos ou metabolitos encontrados nas plantas. Sobretudo, em ervas e outros produtos de origem natural encontrados em plantas, o que inclui os seus derivados químicos, onde representam $50 \%$ de todos os medicamentos utilizados no mundo. Visto isso, a utilização das plantas para fins medicinais começou a milhares de anos como forma de prevenir e tratar diversas doenças.

Em meio a crença popular sobre a utilização das plantas medicinais, apesar de não serem aconselhadas pela comunidade científica, algumas técnicas ainda permanecem e fazem parte do cotidiano das mães que buscam o cuidado dos filhos, que são passadas de geração em geração. Além disso, essas plantas representam um papel de grande importância terapêutica, uma vez que possuem características reconhecidas como cura, tratamento, prevenção ou diagnóstico de doenças (Santana et al., 2018).

Oliveira et al., (2018) mostraram ainda que na maioria das vezes a utilização das plantas medicinais ocorre sem a indicação de um profissional capacitado e habilitado para este fim, mas, em sua grande maioria através do conhecimento popular passado de pai para filho. Dessa forma, as pessoas mais idosas dispõem de um maior conhecimento sobre a utilização dessas plantas de uso medicinal.

A utilização terapêutica de algumas plantas com efeitos medicinais são consideradas eficientes no tratamento de muitas doenças. Ao observar a eficácia de algumas delas, a erva cidreira, capim santo, hortelã, endro e mamona passaram a ser 
utilizadas com maior frequência, uma vez que estas apresentam resultados imediatos. Dessa forma, obtendo bons resultados, a população é impulsiona cada vez mais a busca por esses tratamentos e métodos (Cavalcanti et al., 2020).

Fabro et al. (2020) corroboram com os dados encontrados na presente pesquisa, uma vez que mostram em seu estudo, que a utilização das plantas medicinais ocorre devido a tradição familiar (43,6\%), acreditar no efeito terapêutico (25,5\%), por ter essas plantas disponíveis no quintal de casa $(9,5 \%)$ e dificuldade em ter acesso ao médico (4,2\%). Além disso, dos 200 participantes entrevistados, 32\% relataram que essa prática ocorreu através dos ensinamentos dos avós, 31\% das mães, $16 \%$ do pai e mãe, $3 \%$ do médico e $3 \%$ de amigos.

Outros estudos também apontam que a obtenção da maioria das plantas é proveniente do quintal (51\%), com familiares, mercado e loja de produtos naturais (24\%), amigos ou até mesmo vizinhos (12\%) e farmácias (9\%). Além disso, cerca de 2,7\% dos participantes do estudo relataram adquirir as plantas nas Unidades de Saúde da Família (USF) de suas comunidades (Zeni et al., 2017).

No estudo realizado por Mattos et al. (2018) com médicos, foi identificada a influência familiar na utilização e orientação de plantas medicinais aos pacientes, onde foi observado que essa prática é muito comum entre a família desses profissionais, sendo que $43 \%$ já utilizaram alguma espécie de planta para fins terapêuticos e entre $50 \%$ essa prática ocorre como um hábito diário. Além disso, foi possível observar que 93\% desses profissionais tiveram origem de famílias que adotam as plantas como uma terapia medicamentosa.

Desta forma, a família desempenha um papel indispensável na transferência dos conhecimentos em relação as plantas medicinais. Uma vez que a maioria da população relata que realiza o tratamento com estes fitoterápicos, para só após procurar os serviços de saúde. A construção desse conhecimento ocorre de forma oral, adquirida por meio da convivência com os membros da família, em especial os mais velhos, e compartilhada entre os demais membros da comunidade (Santana et al., 2018).

Rodrigues et al., (2020), ainda complementam que a transmissão desses conhecimentos ocorre entre pais e/ou avós, sendo a família a razão pela qual a população mais utiliza as plantas medicinais, uma vez que os costumes e ensinamentos são passados de pai para filho. Dessa forma, o contato familiar é indispensável na transmissão do conhecimento através da oralidade. No entanto, também foi apontado pelos autores que as condições socioeconômicas e a baixa escolaridade não possuem influência sobre os conhecimentos adquiridos em relação as plantas medicinais (Cavalcanti et al., 2020).

No entanto, outro fator que merece destaque se relaciona aos fatores que alteram ou eliminam o grau de conhecimento da população sobre as plantas medicinais, que pode estar envolvida com o aumento da marginalização em comunidades tradicionais. Com isso, há o abandono das práticas antigas e dos ritos e costumes que provocam uma redução na importância da utilização dessas plantas entre as comunidades além de interromper o processo histórico de transferência e experimentação de conhecimentos para as próximas gerações (Mera et al., 2018).

Krupek e Nedopetalski (2020) ainda apontam que outros problemas são comuns, tais como a diversidade de nomes dado a uma única espécie (Melissa officinalis - erva cidreira ou cidró) e a utilização de um mesmo nome para diferentes plantas (pulmonária - Stachys byzantina e Pulmonaria officinalis). Esse tipo de conflito de informações na comunidade pode gerar confusões em relação a utilização correta e identificação da espécie.

Dentre as plantas com fins medicinais mais utilizadas pelos pais, Fabro et al. (2020) apontaram em seu estudo que 11,41\% utilizam marcela, 10,51\% cidreira (Melissa officinalis), 9,61\% hortelã (Mentha spicata), 4,8\% losna, 4,5\% alcachofra e $3,6 \%$ camomila. Sendo que, no presente estudo as ervas mais utilizadas foram camomila (17,5\%), cidreira (8,8\%), e boldo $(8 \%)$.

Já no estudo realizado por Silva e Oliveira (2017), das 27 espécies de plantas medicinais citadas pelos participantes do estudo, as mais utilizadas foram: hortelã, manjericão, poejo e marcela. Resultado este semelhante ao apresentado por 
Szerwieski et al. (2017) que revelaram as ervas mais utilizadas como sendo: hortelã, marcela e poejo.

Ao se analisar as indicações realizadas por amigos, foi identificado que $30 \%$ indicam a camomila e $20 \%$ o capim limão. Entre os familiares houve a indicação de 19,05\% de camomila e 9,52\% de hortelã e melissa. Já na indicação médica as plantas mais indicadas foram a hortelã (25\%) e a camomila (20\%) (Oliveira et al., 2018).

Visto isso, a marcela é frequentemente utilizada para o tratamento de problemas no estomacais; a hortelã como antigripal, vermífugo e calmante; o manjericão e o poejo para tratar gripes sob a forma de infusão. Essas plantas são utilizadas principalmente para o tratamento ou a prevenção da má digestão (64\%), gripe (52\%), resfriado (42\%), inflamação (34\%) e cólica (28\%) (Silva \& Oliveira, 2017).

Cavalcanti et al., (2020) identificaram em seu estudo que $23 \%$ da população utiliza a mamona (Ricinus communis) como forma de reduzir a cefaleia, dor de ouvido e dor de dente, onde o óleo é extraído e espalhado no sentido da dor. Além disso, foi observado que 15\% da população utiliza o capim santo (Cymbopogon citratus), boldo (Peumus boldus) e a erva cidreira para o alívio de dores abdominais, além de seu efeito como calmante. A hortelã foi citado por $8 \%$ dos participantes, onde a sua utilização ocorre com o objetivo de diminuir ou curar os sintomas da gripe. Já o endro (Anethum graveolens), romã (Punica granatum) e gengibre (Zingiber officinale) foram citados em $8 \%$ da amostra onde são consumidos para estimular a digestão e infecção, muito utilizados para amenizar dores na garganta, respectivamente.

Oliveira et al., (2018) ainda apontam em seu estudo que a finalidade mais relatada para a utilização dessas plantas foi para o tratamento como calmante, sendo as mais citadas a camomila, capim limão, erva cidreira, erva doce, hortelã e melissa, sendo as menos utilizadas o alecrim, erva de São João e folha de maracujá. Segundo o Formulário Nacional Fitoterápico o capim limão, camomila, folha de maracujá, erva cidreira e melissa são utilizadas com esta finalidade. No entanto, algumas plantas utilizadas não possui a finalidade de calmante, tais como: hortelã, alecrim e erva de São João, sendo a maioria das plantas classificadas como responsáveis por apresentar efeitos ansiolíticos e sedativos leves.

Dessa forma, a camomila se relaciona com o fato de possuir propriedades fitoterápicas sedativas e digestivas; a cidreira além de possuir um sabor agradável, é utilizada como um calmante; a hortelã em problemas do aparelho respiratório e digestório; o boldo para problemas no fígado e digestão; o guaco sendo utilizado como um broncodilatador, expectorante e antitussígeno; o alecrim para problemas digestivos, hipertensão, sintomas de reumatismo e perda de apetite; e a macela sendo utilizada principalmente para problemas digestórios, sedativo e cólica de origem menstrual e nervosa. Dessa forma, é perceptível que a maioria dos motivos pelo qual a população faz o uso das plantas medicinais é para o tratamento de gripes, resfriados, cólicas, insônia e enxaqueca (Stefanello et al., 2018).

Dentre as plantas medicinais mais citadas no estudo, a erva cidreira possui o nome científico de Melissa officinalis pertencente à família Lamiaceae, esta é reconhecida e recomendada pela sua ação de calmante natural, uma vez que a erva possui elevadas quantidades de limoneno, citral, carvona, e mirceno, os quais possuem ação comprovada no combate a inflamação, dor e atividades ansiolíticas (Ferreira et al., 2021).

Já a camomila (Matricaria recutita) é uma das ervas mais utilizadas, uma vez que possui propriedades antiespasmódicas e anti-inflamatórias atuando principalmente na indigestão, diarreia, enjoo, vômitos, náuseas e anorexia, além de ser muito utilizada em cólicas infantis (Linhares et al., 2018; Vaz \& Vieira, 2021). Por sua vez, o boldo também pertencente à família Lamiaceae, sendo uma das espécies mais utilizadas no combate a dor e desconfortos estomacais (Neri et al., 2018).

Stefanello et al. (2018) ainda apontam que algumas espécies de plantas com fins medicinais são comumente utilizadas na culinária como forma de tempero (cebola e alho), condimentos (gengibre e canela) e no preparo de refolgados e saladas (couve e chicória). No cotidiano facilmente se encontra espécies para uso medicinal e culinário ao mesmo tempo, sendo essas plantas utilizadas para o tratamento da saúde e na culinária. As espécies mais utilizadas para essas finalidades são: sálvia, salsinha, alecrim, cebola, alho, hortelã, alfavaca, gengibre, canela e noz-moscada. 
Visto isso, a eficácia e a segurança durante a utilização das plantas medicinais irão depender da correta identificação da planta, uma vez que o indivíduo deve ter conhecimento sobre o modo de preparo, forma de uso, fragmento da planta a ser utilizado e a dose apropriada, fato este que é muito influenciado pelos saberes da utilização popular e evidenciado por estudos científicos. No entanto, assim como todo fármaco, a utilização da planta medicinal pode levar ao aparecimento de efeitos adversos, seja pelo uso inadequado, isolado, crônico, em associação com outras plantas, fitoterápicos ou até mesmo a medicamentos convencionais (Pedroso et al., 2020).

No estudo realizado por Queiroz et al., (2017) foram entrevistadas 21 pessoas, no qual 15 foram do sexo feminino e 6 do sexo masculino, onde identificou-se que entre as comunidades a utilização das plantas medicinais ocorre através do chá, xarope, banho, pomada, garrafada e outras formas. Dado este que vai de encontro aos encontrados na pesquisa, uma vez que a prevalência foi de chás seguida por xarope.

Zeni et al. (2017) ainda mostraram em seu estudo que $87,4 \%$ da forma de consumo das plantas medicinais é através do chá; $5,3 \%$ suco; $1,3 \%$ xarope e pomada; e $0,7 \%$ compressas, gargarejo, banhos de assento e garrafadas. Onde o preparo da garrafada só foi descrita por um participante do estudo, no qual misturou diversas plantas como forma de obter um produto com efeito mais eficaz.

Os principais métodos de preparo das plantas medicinais se resume em infusão, decocção, lambedor, xarope e garrafada. Além disso, algumas literaturas ainda apontam os preparos em formas de pó, imersão e pomada. Esses dados se justificam na praticidade dos preparos caseiros, que na maioria das vezes são obtidos através de decocção e infusão, onde esses extratos são baseados através de experiências adquiridas no decorrer da vida ligada fortemente a costumes e tradições socioculturais (Sganzerla et al., 2021).

A utilização de algumas plantas ainda ocorrem de forma errônea pela comunidade, a exemplo do boldo que comumente é macerado em água fria. No entanto, a maceração dessa erva não é indicada pelo Manual de Fitoterápicos da Farmacopeia Brasileira, a orientação correta é sob a forma de chá infuso (Krupek \& Nedopetalski, 2020).

Ao se analisar as partes mais utilizadas das plantas, foi possível observar que a maioria dos estudos acabam descrevendo mais de uma estrutura do vegetal utilizado em seus preparos. No entanto, as folhas foi a estrutura com maior destaque entre as espécies, no qual as flores foram as menos utilizadas. A maior utilização das folhas justifica-se pela facilidade na coleta, secagem e armazenamento, quando comparada a outras estruturas como cascas, raízes, frutos e flores. Além disso, a utilização da folha nos preparos promove uma conservação no recurso vegetal uma vez que não impede a reprodução e o desenvolvimento da planta (Sganzerla et al., 2021).

Além disso, Krupek e Nedopetalski (2020) ainda relatam que a principal forma de utilização das plantas de um modo geral ocorre através do chá. Dessa forma, a apresentação correta dessas espécies é crucial para obtenção dos efeitos medicinais desejados e que não seja prejudicial à saúde, tendo em vista que algumas espécies quando preparadas na forma de chá tornamse danosas ao ser humano, uma vez que algumas plantas quando ingeridas possuem um alto grau de toxicidade.

Dessa forma, o preparo dos remédios caseiros se resume em chás e xaropes. No qual o xarope é a forma de preparo mais indicada para o tratamento das doenças do trato respiratório, mesmo quando misturados ao mel de abelha ou açúcar. Onde a utilização desses ingredientes pode se relacionar ao paladar e por se tratar de fontes de energia, uma vez que o indivíduo necessita de forças pra restabelecer as defesas do organismo (Leal et al., 2019).

Ribeiro et al. (2020) observaram que do total de participantes do estudo, 34\% obtiveram as plantas medicinais através de familiares e vizinhos, 33\% acabaram cultivando em casa, 13\% adquiram em lojas, $12 \%$ em feiras livres e $4 \%$ em supermercados. Oliveira e Lucena (2015), ainda apontaram em seu estudo que $85 \%$ da amostra total envolvida na pesquisa cultivavam as plantas medicinais na própria residência.

Cavalcanti et al., (2020) ainda apontam que $84 \%$ dos participantes do estudo cultivaram as plantas medicinais no 
próprio quintal, outros $8 \%$ adquiram em mercados e outros $8 \%$ sempre que necessitaram das plantas conseguiram facilmente com vizinhos e familiares. No qual, $100 \%$ fizeram o uso de plantas medicinais desde que nasceram através do intermédio de familiares.

Além disso, cerca de $91,9 \%$ da população brasileira utilizam as plantas medicinais como forma de tratamento natural para algumas enfermidades, no qual desse total $46 \%$ realizam o cultivo dessas ervas na própria residência. Sendo o método de tratamento alternativo muito procurado pela população, sobre tudo por sua eficácia e por possuir um baixo custo (Ethur et al., 2011).

A comercialização das plantas medicinais ocorrem de diversas formas, tais como: casca, raiz, caule, fruto, folhas, entre outras. Em um estudo realizado no mercado central da cidade de Patos-PB, foi identificado que as plantas são mais vendidas na forma de casca + raízes e raízes + folhas, cada uma com $22,2 \%$, casca e folhas $(11,2 \%)$ e casca e raiz também com $22,2 \%$. Em outro estudo foi apontado que as partes vegetais mais utilizadas foram as folhas (37\%) seguido das cascas (23\%). Além disso, no estudo foram identificadas 36 espécies de plantas medicinais, sendo as mais vendidas o cajueiro (13\%), aroeira (13\%) e barbatimão (11\%) (Medeiros et al., 2019).

Dessa forma, quando utilizados corretamente, os produtos a base de plantas medicinais são considerados seguros. Em um estudo realizado com equipes multiprofissionais de saúde Mattos et al. (2018) verificaram que $96 \%$ desses profissionais observaram melhoras nos quadros clínicos dos pacientes que utilizaram as plantas medicinais, sendo estas associadas ou não a outros tipos de medicamentos. Além disso, cerca de $87 \%$ dos profissionais prescreveram ou sugeriram aos pacientes a utilização de alguma planta medicinal.

\section{Conclusão}

Através da realização do estudo foi possível identificar que a tradição familiar em utilizar plantas medicinais no tratamento de doenças nos filhos foi de 73,1\%. 90,29\% dos entrevistados relataram que adquiriram conhecimento e tiveram acesso a essas plantas em casa, com os pais ou os avós, sendo a herança familiar uma das principais fontes de obtenção dessas informações.

Além disso, foi observado que a planta mais utilizada é a camomila (17,5\%), sendo a forma de consumo o chá $(92,4 \%)$ através de plantas obtidas na própria residência $(51,89 \%)$. Ao se analisar a eficácia das plantas, foi apontado por 94,5\% dos participantes que a terapia alcançou o efeito desejado. Desse modo, observou-se que a utilização das plantas medicinais é fortemente presente entre os pais do município de Cajazeiras-PB. Além disso, a presente pesquisa remete a necessidade em investimentos em novos estudo, uma vez que a temática "plantas medicinais utilizadas na pediatria" ainda é pouco abordada na literatura nacional.

\section{Referências}

Alves, A. R., \& Silva, M. J. P. D. (2003). O uso da fitoterapia no cuidado de crianças com até cinco anos em área central e periférica da cidade de São Paulo. Revista da Escola de Enfermagem da USP, 37, 85-91.

Andrade, M. M. (2009). Introdução à metodologia do trabalho científico: elaboração de trabalhos na graduação. Atlas.

Baracuhy, J. D. V., Furtado, D. A., Francisco, P. R. M., Lima, J. D., \& Pereira, J. P. G. (2016). Plantas Medicinais de uso comum no Nordeste do Brasil. Plantas Medicinais de uso comum no Nordeste do Brasil. Campina Grande: UFCG.

Bardin, L. (2011). Análise de conteúdo. Edições, 70, 1977p.

Brasil. Ministério da Saúde. (2016). Secretaria de Ciência, Tecnologia e Insumos Estratégicos. Departamento de Assistência Farmacêutica. Política e Programa Nacional de Plantas Medicinais e Fitoterápicos. Brasília: Ministério da Saúde.

Brasil. Ministério da Saúde. (2006). Secretaria de Assistência à Saúde. Departamento de Atenção Básica. Política Nacional de Práticas Integrativas e Complementares no SUS: PNPIC-SUS. Brasília: Ministério da Saúde. 
Brito, M. F., Marín, E. A., \& Cruz, D. D. D. (2017). Plantas Medicinais nos Assentamentos Rurais em uma Área de Proteção no Litoral do Nordeste Brasileiro. Ambiente \& Sociedade, 20, 83-104.

Cavalcante, A. C. P., \& Silva, A. G. (2014). Levantamento etnobotânica e utilização de plantas medicinais na comunidade Moura, Bananeiras-PB. Revista Monografias Ambientais, 13(2), 3225-3230.

Cavalcanti, C. A., Andrade, Y. V. S., \& Lima, C. G. (2020). Estudo Etnobotânico sobre a contribuição do uso de plantas medicinais utilizadas no Sítio Frexeira Velha, pertencente ao Município de Pesqueira-PE. Brazilian Journal of Development, 6(12), 94929-94940.

Duarte, A., Masiero, A. V., Boff, P., \& Pucci, M. O. (2020). Saberes e práticas populares no uso de plantas medicinais em espaço urbano no planalto sul catarinense. Revista Brasileira de Agroecologia, 15(1), 27-39.

Ethur, L. Z., Jobim, J. C., Ritter, J. G., Oliveira, G., \& Trindade, B. S. (2011). Comércio formal e perfil de consumidores de plantas medicinais e fitoterápicos no município de Itaqui-RS. Revista Brasileira de Plantas Medicinais, 13, 121-128.

Fabro, M., Ramos, F. A, \& Souza, P. A. (2020). Identificação das plantas medicinais usadas pelos moradores da região da AMURES (Associação dos Municípios da Região Serrana). Research, Society and Development, 9 (7), e994975230-e994975230.

Fernandes, P., \& Boff, P. (2017). Medicinal plants in the family farms of rural areas in southern Brazil: ecological and ethnobotanical aspects. Boletín Latinoamericano y del Caribe de Plantas Medicinales y Aromáticas, 16(5), 493-505.

Ferreira, MV, Lebuino, LP, \& Santos, JS (2021). Plantas medicinais de uso tradicional na região sul paraense: um estudo etnobotânico. Research, Society and Development, 10 (12), e592101220778-e592101220778.

Krupek, R. A., \& Nedopetalski, P. F. (2020). O uso de plantas medicinais pela população de União da Vitória-PR: o saber popular confrontado pelo conhecimento científico. Arquivos do Mudi, 24(1), 50-67.

Leal, J. B., Silva, M. M., Costa, J. M., Albuquerque, L. C. D. S., da Silva Pereira, M. D. G., \& de Sousa, R. L. (2019). Etnobotânica de plantas medicinais com potencial anti-inflamatório utilizadas pelos moradores de duas comunidades no município de Abaetetuba, Pará. Biodiversidade, 18(3).

Leite, N. D. A. (2019). A utilização da etnobotânica na fisioterapia: conhecimentos e práticas do uso de plantas medicinais e fitoterápicos.

Levine, D. M., Berenson, M. L., \& Stephan, D. (2000). Estatística: Teoria e Aplicações usando Microsoft Excel em Português. Rio de Janeiro: LTC.

Linhares, K. M., Silva, K. V., Ponciano, C. S., Pontes, E. D. S., Lima, M. W. S., \& Medeiros, F. D. (2018). Avaliação do Uso da Camomila no Tratamento da Ansiedade. International Journal of Nutrology, 11(S 01), Trab171.

Mattos, G., Camargo, A., Sousa, C. A. D., \& Zeni, A. L. B. (2018). Plantas medicinais e fitoterápicos na Atenção Primária em Saúde: percepção dos profissionais. Ciência \& Saúde Coletiva, 23, 3735-3744.

Medeiros, F. S., Sá, G. B., Dantas, M. K. L., \& das Gracias Almeida, M. (2019). Plantas medicinais comercializadas na feira livre do município de Patos, Paraíba. Revista Verde de Agroecologia e Desenvolvimento Sustentável, 14(1), 150-155.

Mera, J. C. E., Rosas, L. V., Lima, R. A., \& Pantoja, T. M. A. (2018). Conhecimento, percepção e ensino sobre plantas medicinais em duas escolas públicas no município de Benjamin Constant-AM. Experiências em Ensino de Ciências, 13(2), 62-79.

Moraes, L. L., Freitas, J. L., Matos Filho, J. R., Silva, R. B., Borges, C. H., \& Santos, A. C. (2019). Etnoconhecimento de plantas medicinais em uma comunidade na Amazônia oriental. Revista de Ciências Agrárias, 42(2), 291-300.

Neri, G. F., Oliveira, T. L., Oliveira, V. J. D. S., \& Brito, N. M. (2018). Uso de plantas medicinais nas unidades de saúde da família do Alto Sobradinho e Cocão do município de Santo Antônio de Jesus-BA. Ensaios e Ciência C Biológicas Agrárias e da Saúde, 22(1), 58-62.

Oliveira, D. S., \& Lucena, E. M. P. (2015). O uso de plantas medicinais por moradores de Quixadá-Ceará. Revista Brasileira de Plantas Medicinais, 17, 407412.

Oliveira, V. B. D., Mezzomo, T. R., \& Moraes, E. F. D. (2018). Conhecimento e uso de plantas medicinais por usuários de unidades básicas de saúde na região de Colombo, PR. Revista Brasileira de Ciências da Saúde, 22(1), 57-64.

Pinto, E. D. P. P., Amorozo, M. C. D. M., \& Furlan, A. (2006). Conhecimento popular sobre plantas medicinais em comunidades rurais de mata atlânticaItacaré, BA, Brasil. Acta botanica brasilica, 20, 751-762.

Queiroz, G. B., Souza, M. O., \& Souza, L. H. (2017). Diversidade na Maneira de uso das Plantas Medicinais em Comunidades Rurais de TremedalBA. Semana de Agronomia da UESB (SEAGRUS) $1(1)$.

Ribeiro, A. F., Valiatti, T. B., Barcelos, I. B., \& Goulart, R. R. (2020). Uso de plantas medicinais pela população do município de Presidente Médici, Rondônia, Brasil. Revista Saúde e Desenvolvimento, 14(19).

Rodrigues, M. B. C., Torres, M. D. O. P., Cavalcante, C. P., Araújo, J. N. G., Vasconcelos, L. P. P. D., Falbo, A. R., \& Moraes, M. M. C. (2013). Uso de plantas medicinais com finalidade de tratamento por cuidadores de crianças atendidas no ambulatório geral de pediatria do Instituto de Medicina Integral Prof. Fernando figueira (IMIP) no período entre novembro de 2012 e janeiro de 2013.

Rückert, B., Cunha, D. M., \& Modena, C. M. (2018). Saberes e práticas de cuidado em saúde da população do campo: revisão integrativa da literatura. Interface-Comunicação, Saúde, Educação.

Sá, R. G. D. (2019). Memória social do uso de plantas medicinais em uma comunidade ribeirinha do Amazonas.

Salomon, D. V. (2004). Como fazer uma monografia. Martins Fontes. 
Research, Society and Development, v. 10, n. 17, e129101724517, 2021

(CC BY 4.0) | ISSN 2525-3409 | DOI: http://dx.doi.org/10.33448/rsd-v10i17.24517

Santana, M. D. O., Sá, J. S., Neves, A. F., Figueredo, P. G. J., \& Viana, J. A. (2018). O Poder das Plantas Medicinais: uma Análise Histórica e Contemporânea sobre a Fitoterapia na visão de Idosas. Multidebates, 2(2), 10-27.

Silva, Á. D. F., Ferreira, G. L., Dias, A. J. A., Barros, N. B., \& Silva, Z. P. N. (2021). Uso e eficácia de plantas medicinais com ações em doenças cardiovasculares e em Diabetes Tipo 2: Panax Ginseng, Curcuma Longa, Adonis Vernalis. Brazilian Journal of Development, 7(9), 86526-86549.

Silva, E. H. (2017). O tema biodiversidade em artigos do encontro de pesquisa em educação ambiental na perspectiva fleckiana. Revista Ibero-Americana de Ciências Ambientais, 8(2), 49-60.

Silva, T. R., \& Oliveira, F. Q. (2017). Levantamento de plantas medicinais utilizadas em domicílios do bairro Maracanã, Prudente de Morais/MG. Revista Brasileira de Ciências da Vida, 5(5).

Sganzerla, C. M., Predebom, A. J., Veloso, J., Corralo, V. S., \& Junior, W. A. R. (2022). Revisão Integrativa Aplicada a Levantamentos Etnobotânicos de Plantas Medicinais no Brasil. Revista Acta Ambiental Catarinense, 19(1), 01-16.

Stefanello, S., Kozera, C., Ruppelt, B. M., Fumagalli, D., Camargo, M. P., \& Sponchiado, D. (2018). Levantamento do uso de plantas medicinais na Universidade Federal do Paraná, Palotina-PR, Brasil. Extensão em Foco, 1(15).

Szerwieski, L. L. D., Cortez, D. A. G., Bennemann, R. M., Silva, E. S., \& Cortez, L. E. R. (2017). Uso de plantas medicinais por idosos da atenção primária. Revista eletrônica de enfermagem, 19.

Vaz, N. C., \& Vieira, A. L. S. (2021). Ação da Camomila-Matricaria recutita L. Para Cólicas em Neonatos: revisão narrativa. Scientia Generalis, 2(2), 142151.

Zeni, A. L. B., Parisotto, A. V., Mattos, G., \& Helena, E. T. D. S. (2017). Utilização de plantas medicinais como remédio caseiro na Atenção Primária em Blumenau, Santa Catarina, Brasil. Ciência \& Saúde Coletiva, 22, 2703-2712. 